\title{
Choosing R\&D or Advertising for Competing Firms in Uncertain Market
}

\author{
Bo Xie, Xianjia Wang \\ School of economics and management, Wuban University (China) \\ xie040304@gmail.com,13971050033@,139.com
}

Received: December 2013

Accepted: June 2014

\section{Abstract:}

Purpose: R\&D and advertising have become important means to enhance the competitiveness of firms' products. Design an appropriate model to help the firm to make the right choice is value in supply chain.

Design/methodology/approach: In considering that whether the market is completely covered or not, we build the strategy selection model for R\&D and advertising for two competing firms and solve the optimal strategy.

Findings: The research results show that when a firm does not take any measures to enhance competitiveness, another firm will neither. However when one takes measures to improve the competitiveness, another will do so, also. When two firms must choose one measure to improve the competitiveness, either in full-covered market or not full-covered market, the two firms will not choose to do advertising in step, even if the firms do not have to pay additional cost in advertising.

Originality/value: In the game model, the firm could compare the own profit in different strategies. According to the above model, the firm choose the right strategy to make the profit maximize in a vertically differentiated market. And when the firm make the choice, it must think about other primary elements such as market.

Keywords: R\&D, advertising, production competition, Hotelling model 


\section{Introduction}

Most economists believe that there are only two methods to enhance firm's competitivenessreform and marketing. In real life, the two methods are expressed by R\&D and advertising. Apple Corp and Samsung Corp are the leaders in the mobile phone market. There is a fierce struggle between them. From the first generation iPhone, Apple Corp continuously improves the performance and application of iPhone. When iPhone $5 \mathrm{~s}$ comes out, consumers find that the refresh rate becomes faster and faster. As the rival, Samsung Corp in order to occupy the mobile phone market takes more and more research and innovation for the mobile phone from the first generation Galaxy to Galaxy 4. We find that Apple Corp and Samsung Corp always pay the money for reform and marketing to attract more consumers and occupy larger market share. In the beverage market, Coca Cola Corp and Pepsi Corp monopolized the cola supply in the market. Due to the uniqueness and non-substitutability of their products, they do not need R\&D but they pay more attention on the marketing. Each year, Coca Cola Corp and Pepsi Corp will pay much money to launch a new and interesting advertisement to attract consumers.

R\&D and advertising can increase consumer's loyalty, and improve the influence in the market and so on. Sosa (2009) proposes that the necessary conditions for R\&D are technology and application. The basic research shows that technology with R\&D can help the firm cross the market and the application with R\&D can help the firm to keep the competitive advantage. This finding is extended to consider the influence of R\&D for the next generation product or the new product in the market by Ofek and Sarvary (2003), Dutta, Narasimhan and Rajiv (1999). Baye and Morgan (2009) model a homogeneous product environment where identical e-retailers endogenously engage in both brand advertising and price advertising. They find that in equilibrium, branding (1) reduces firm profits; (2) increases prices paid by loyalty and shoppers, and (3) reduces the information value provided by comparison sites. Anderson and Simester (2013) consider that the model of competition predicts that firms will sell less when competitors target their customers with advertising. They compare how these positive spillovers vary across product categories to illustrate the importance of product standards, customer learning, and switching costs. The findings have the potential to change our understanding of competition in mature markets. Gardete (2013) considers a cheap-talk model in which a firm has a chance to communicate its product quality to consumers. The model describes how advertising can be both informative to consumers and profitable for the firm through its content, in a vertically differentiated market.

The input of $R \& D$ and advertising has a close relationship with the profit of the firms in future, which means more input more profit. The resource of the firm is limited, so the firm must consider the return of investment. Many scholars compare the influence of R\&D and advertising. Steenkamp and Fang (2011) think about the critical role of R\&D and advertising in the marketing strategy of the firm. Then they conceptually and empirically examine why and how much the effectiveness of these two marketing instruments differs between times of 
economic expansions versus periods of economic contractions-and whether these results depend on the cyclicality of the industry. These findings provide valuable and actionable insights into how firms should respond to contractions in order to increase profits and market share. Fosfuri and Giarratana (2009) investigate the impact of rivals' product innovation and new advertising on a firm's financial market value in mature product markets. They find that the effect of new advertising is channeled through market size dynamics, while that of product innovation operates through market share dynamics. Grossmann (2008) develops a qualityladder model of endogenous growth to study the interplay between in-house $R \& D$ and combative advertising expenditure, and its implications for economic growth, firm size, and welfare. They find that first, if firms incur higher sunk costs for marketing, concentration and firm size rise. Second, firm size and R\&D expenditure are positively related as larger firms are able to offset R\&D costs through higher sales. The analysis also suggests that R\&D subsidies are conducive to $R \& D$ and growth without inducing firms to raise advertising outlays. Mizik and Jacobson (2003) consider that firms allocate their limited resources between two fundamental processes of creating value and appropriating value. They address this issue by examining the effect that shifts in strategic emphasis have on stock return. They find that the stock market reacts favorably when a firm increases its emphasis on value appropriation relative to value creation.

This paper analyzes that the two competing firms have a unique product competing in the market and in order to enhance the competitiveness, they must make the choice for R\&D and advertising with the limited capital. This paper examines two cases markets i.e. full-covered market (Coca-Cola and Pepsi Cola) and not full-covered market (Apple and Samsung), and discuss that which choice is the optimal strategy in the different types of the market. Interesting findings are that even advertising without cost, too much advertising would bring a reduction of the profits for two competing firms and make the firms in a disadvantage situation. In the full-covered market and not full-covered market, the optimal choices for two firms maybe same or different.

\section{Model and Analysis}

In this section, we develop a model with two competing firms $A$ and $B$, each with a competing product. In order to improve their market competitiveness and scale, the firms need to invest on reform and marketing in terms of, $R \& D$ and advertising. These two methods will increase the consumers' utility to bring more sales for firms. We use the demand model presented by Hotelling (1929). We assume that firm $A$ and firm $B$ are located at a distance in the market, the distance is $M$. When the value of $M$ is small, which means that the competition is intense. We think about two cases for the market: (1) the full-covered market, the consumer will buy 
the product from one firm, see Figure $1 ;(2)$ the not full-covered market, the consumer can buy nothing from two firms, see Figure 2.

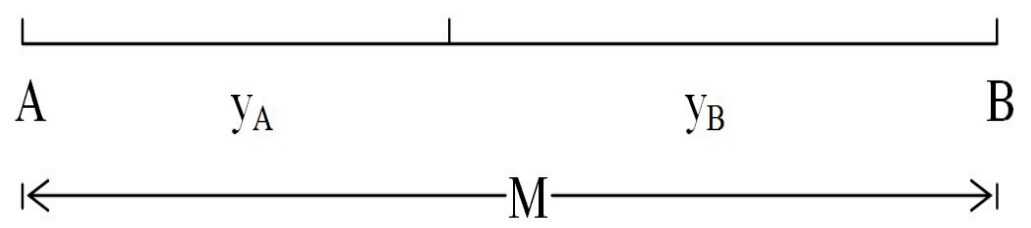

Figure 1. The full-covered market

Where $y_{i}$ is the consumer's preference distance when buy the product from firm $i, i \in(A, B)$, and the market demand for firm is $q_{i}=y_{i}$.

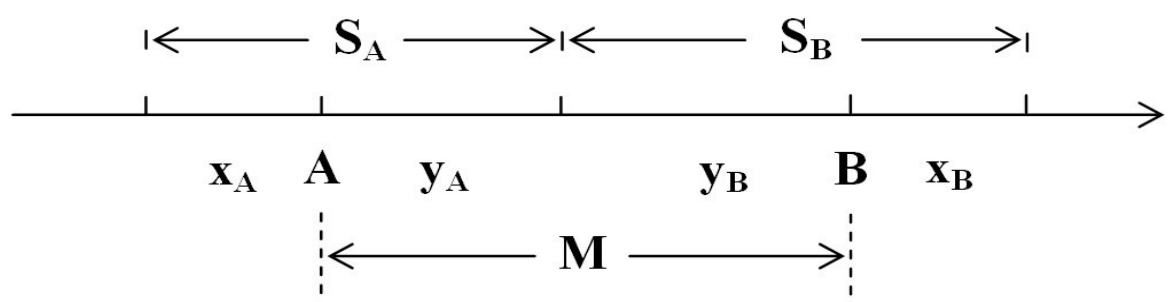

Figure 2. The not full-covered market

Where $x_{i}$ is the consumer's preference distance outside the two firms and the market demand for firm $i$ is $q_{i}=S_{i}=x_{i}+y_{i}$.

We assume that the reservation price for consumer is $R, t$ is the transport cost and $p_{i}$ is the price. For the convenience of calculation, we reference Xu, Gurnani and Desiraju (2010) hypothesis $t=1$. So when a consumer buys the product, his utility is:

$$
U_{i}(d)=R-d_{i}-p_{i}
$$

Next we consider the consumer's utility with R\&D or advertising. When the firm $i$ invests on $R \& D$, the investment cost is $\frac{e_{i}^{2}}{2}$ and the increasing consumer's utility is $e_{i}$. So the consumer's utility changes to:

$$
U_{i}(d)=R-d_{i}-p_{i}+e_{i}
$$


When firm $i$ advertises, the advertising will bring the increasing utility $\theta N_{i}$ for consumer, where $N_{i}$ is the number of consumers buying the product from firm $i$, and $\theta$ is the effect parameter of the advertising. So the consumer's utility changes to:

$$
U_{i}(d)=R-d_{i}-p_{i}+\theta N_{i}
$$

For firm $i$, when it makes R\&D, the profit function is $\pi_{i}=p_{i} q_{i}-\frac{e_{i}^{2}}{2}$; when it makes advertisement, the profit function is $\pi_{i}=p_{i} q_{i}-F$. We assume that firm has the limited fund and capital so it has to choose only one measure to improve the competitiveness at one time. In further, we assume that advertising without additional cost with two main reasons: first, in real life, advertising has become the most important means of marketing strategy. Therefore each firm has a fixed cost of advertising in market expenditure. Secondly, we think that the firm use the advertisement to instill an idea to its consumers such as Sony Corp uses the advertisement to let the consumers know that PS2 can be achieved on the online game function with the same firm product; Samsung Corp advertises that the consumers with Galaxy 4 can send and achieve the consumer's information without network or cost and the consumers with Note 3 can use the mobile phone's screen to achieve the joint synchronization function. These advertisements use the theory that in the market a consumer will get extra utility from purchasing products when he knows more consumers are using the same product as him.

In this paper we introduce two types of market as full-covered market and not full-covered market. The first market means that each consumer buys one unit of the product from either of the two firms when the two firms occupy the whole market. The second market means that the consumer can buy the product from others firms outside the two firms. We discuss the optimal strategy for the competing firms when they face the choice of R\&D and advertising in the two kinds of the market. The paper will research the problem on three ways: (1) in the two types market only R\&D or no action can be chosen; (2) in the two types market only advertising or no action can be chosen; and (3) in the two types market, the firms must choose an action between R\&D and advertising. This paper would discuss the above three circumstances for two firms with the competing product in the market and solve the optimal strategy. Assume that the two firms choose the strategy and price simultaneously without leader or follower. 


\subsection{The Firms Just Choose R\&D or No Action}

When the firms just can increase the consumer's utility by $R \& D$, the firms can choose R\&D or no action, the profits for the firms are listed in Table 1:

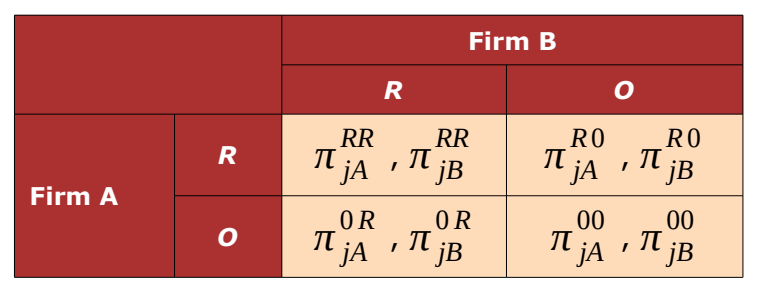

Table 1 . The profits with R\&D or no action

Where $\pi_{j i}^{T}$ is the profit for firm $i$ in mark $j$ choosing strategy $T, i \in(A, B), j \in(F, D)$ and $T \in\{(0,0),(R, 0),(0, R),(R, R)\}$. Then $F$ represents the full covered market and $D$ represents the not full-covered market. $R$ is denoted the firm choosing R\&D and 0 is denoted the firm having no action. Further, we use the abbreviations $R R$ to denote the strategy for two firms, the first (second) letter denoting the action for firm $A$ (firm $B$ ).

By the Hotelling model, we can get the demand function in the full-covered market (see Appendix 1a), and get the profits for the two firms as follows:

$$
\begin{gathered}
\pi_{F A}^{R R}=M^{2} / 2=\pi_{F B}^{R R} \\
\pi_{F A}^{R 0}=\frac{9 M^{2}}{16}>\frac{49 M^{2}}{128}=\pi_{F B}^{R 0} \\
\pi_{F A}^{0 R}=\frac{49 M^{2}}{128}<\frac{9 M^{2}}{16}=\pi_{F B}^{0 R} \\
\pi_{F A}^{R R}=\frac{4 M^{2}}{9}=\pi_{F B}^{R R}
\end{gathered}
$$


We also get the demand function for two firms in not full-covered market (see Appendix 1b), and the profits as follows:

$$
\begin{gathered}
\pi_{D A}^{R R}=\frac{3}{50}(M+2 R)^{2}=\pi_{D B}^{R R} \\
\pi_{D A}^{R 0}=\frac{147(M+2 R)^{2}}{716}>\frac{5043(M+2 R)^{2}}{256328}=\pi_{D B}^{R 0} \\
\pi_{D A}^{0 R}=\frac{5043(M+2 R)^{2}}{256328}<\frac{147(M+2 R)^{2}}{716}=\pi_{D B}^{0 R} \\
\pi_{D A}^{R R}=\frac{537(M+2 R)^{2}}{5329}=\pi_{D B}^{R R}
\end{gathered}
$$

To analyze the above results, we can get the optimal strategy for two firms in the full-covered market and not full-covered market.

Proposition 1. In the two kinds (full-covered and not full-covered) of the market, if firm $A$ and firm $B$ just can choose R\&D or no action, both firms doing R\&D is the Nash equilibrium.

In the full-covered market, the two firms play the game and get the result in prisoner dilemma problem: the profits for the two firms choosing R\&D are less than that for both no actions $\left(\pi_{F i}^{R R}=\frac{4 M^{2}}{9}<\frac{M^{2}}{2}=\pi_{F i}^{00}\right)$. By doing R\&D, firms expect to increase the utility for consumers buying the product, occupy more market share and gain greater profits. But with the result from the calculations, we find that when two firms both choose R\&D simultaneously, they will pay the same level of effort $e_{A}=e_{B}=\frac{M}{3}$. And we get $p_{i}^{R R}=p_{i}^{00}$ and $q_{i}^{R R}=q_{i}^{00}$ (see Appendix 2a). It means that when two firms both choose R\&D, the increasing consumer's utility has no effect for price and sales. The firms have to pay some cost for R\&D, so the total profit is not increasing but decreasing $\pi_{F i}^{R R}<\pi_{F i}^{00}$. When one firm chooses R\&D and another chooses no action, the firm with no action will lose some market share, it drives another firm to reduce the price to seize the market and the profit for another firm is decreasing. Another firm doesn't want to see the bad result for itself, so it will do R\&D, too. So in the full-covered market, even the two firms could get more profits in strategy 00 , strategy $R R$ is the unique Nash equilibrium strategy. 
In the not full-covered market, the profits for the two firms choosing R\&D are more than that for both no actions $\left(\pi_{D i}^{R R}=\frac{537(M+2 R)^{2}}{5329}>\frac{3(M+2 R)^{2}}{50}=\pi_{D i}^{00}\right)$. Because when the firm chooses R\&D, the utility of the consumer will increase, the firm can price highly. The market is not completely covered, the increasing for the price does not sacrifice the sales as condition, and the product sales also increase. In this case, even the firm must pay a certain cost for R\&D, the ultimate profit is increasing. So in the not full-covered market, the firms can get more profits by $R \& D$ and both $R \& D$ is the Nash equilibrium solution.

So in the two kinds of the market, the two firms will both choose R\&D to keep the competitive, even sometimes $R \& D$ will sacrifice the profit. The two firms both do $R \& D$ to develop the product in the market which is good for the consumers.

\subsection{The Firms Just Choose Advertisement or No Action}

When the firms just can increase the consumer's utility by advertising, the firms can choose advertising or no action, the profits for the firms are listed in Table 2:

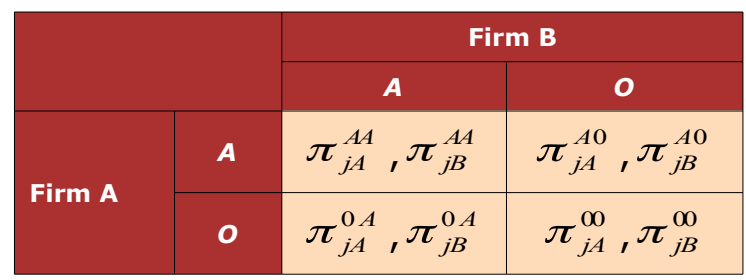

Table 2. The profits with advertising or no action

Where $\pi_{j i}^{T}$ is the profit for firm $i$ in market $j$ choosing strategy $H, i \in(A, B), j \in(F, D)$ and $H \in\{(0,0),(A, 0),(0, A),(A, A)\} . A$ is denoted that the firm chooses advertising and 0 is denoted that the firm has no action. Further, we use the abbreviations $A A$ to denote the strategy for two firms, and the first (second) letter to denote the action for firm $A$ (firm $B$ ).

By the Hotelling model, we can get the demand function in the full-covered market (see Appendix $1 \mathrm{c}$ ), and get the profits for the two firms as follows:

$$
\begin{gathered}
\pi_{F A}^{00}=M^{2} / 2=\pi_{F B}^{00} \\
\pi_{F A}^{A 0}=-\frac{M^{2}(-3+\theta)^{2}}{9(-2+\theta)}>-\frac{M^{2}(-3+2 \theta)^{2}}{9(-2+\theta)}=\pi_{F B}^{A 0}
\end{gathered}
$$




$$
\begin{gathered}
\pi_{F A}^{0 A}=-\frac{M^{2}(-3+2 \theta)^{2}}{9(-2+\theta)}<\frac{M^{2}(-3+\theta)}{9(-2+\theta)}=\pi_{F B}^{0 A} \\
\pi_{F A}^{A A}=-\frac{M^{2}(-1+\theta)}{2}=\pi_{F B}^{A A}
\end{gathered}
$$

We also get the demand function for two firms in not full-covered market (see Appendix 1d), and the profits as follows:

$$
\begin{gathered}
\pi_{D A}^{00}=\frac{3}{50}(M+2 R)^{2}=\pi_{D B}^{00} \\
\pi_{D A}^{A 0}=-\frac{(-3+2 \theta)(-7+3 \theta)^{2}(-M-2 R+M \theta+R \theta)^{2}}{(-2+\theta)(-1+\theta)\left(35-35 \theta+8 \theta^{2}\right)^{2}}=\pi_{D B}^{0 A} \\
\pi_{D A}^{0 A}=\frac{(-3+\theta)(-7+4 \theta)^{2}(-M-2 R+M \theta+R \theta)^{2}}{(-2+\theta)\left(35-35 \theta+8 \theta^{2}\right)^{2}}=\pi_{D B}^{A 0} \\
\pi_{D A}^{A A}=-\frac{3(-M-2 R+M \theta)^{2}}{50(-1+\theta)}=\pi_{D B}^{A A}
\end{gathered}
$$

To analyze the above results, we can get the optimal strategy for two firms in the full-covered market and not full-covered market.

Proposition 2. In the full-covered market, whatever another firm chooses advertising or not, the optimal choice for one firm is no action.

Through the proposition 1, we know in the full-covered market, even if R\&D brings a certain cost, the optimal choice for two firms is choosing R\&D simultaneously still. People think that if advertising is no cost $(F=0)$, both firms choosing advertising must be the optimal choice for them. But we can get $\pi_{F i}^{A A}<\pi_{F i}^{00}$ from the calculation that no action for both firms is Nash equilibrium. The reason is that although advertising can improve the consumption utility of consumers, the impact by advertising on price is uncertain. Advertising will produce two interactions on price: one is that advertising makes the price increase, because of the utility of consumers increasing; another is that advertising makes the price decrease, because of the good value increasing and demand increasing. In other words, when one firm advertising for increasing the good value and demand, because the market is full-covered, its increasing 
demand is grabbed from its rival. Rival with market share dropping is more willing to reduce price to attract more consumers. Because there is no additional cost for advertising in this paper, one firm will increase the intensity of advertising more and more, another firm will reduce the price in order to attract consumers. These actions of two firms make the competition based on price more and more intense, so that the profits for two firms will reduce. When two firms both take the advertisement which affects each other, they will have the strong power to continuously reduce the price to snatch the market share and finally their profit is less than that under another three strategies. By calculation results we will get the profits order of two firms in different strategies as $\pi_{F A}^{A A}<\pi_{F A}^{0 A}<\pi_{F A}^{A 0}<\pi_{F A}^{00}$ and $\pi_{F B}^{A A}<\pi_{F B}^{0 A}<\pi_{F B}^{A 0}<\pi_{F B}^{00}$.

The market is fully covered that is an especially important condition for Proposition 2. It makes that the firm gets the additional demand from its rival. With losing the market share, the rival will take response to reduce the competitive price to attract more consumers. In the following discussion, we will show the different result by advertising in the not full-covered market.

In the not full-covered market, we know that the market share is different with the market demand. Through calculating, we get the optimal strategy about parameters $\theta$ and $R$ for firm $i$, the optimal strategy as shown below in Figure 3:

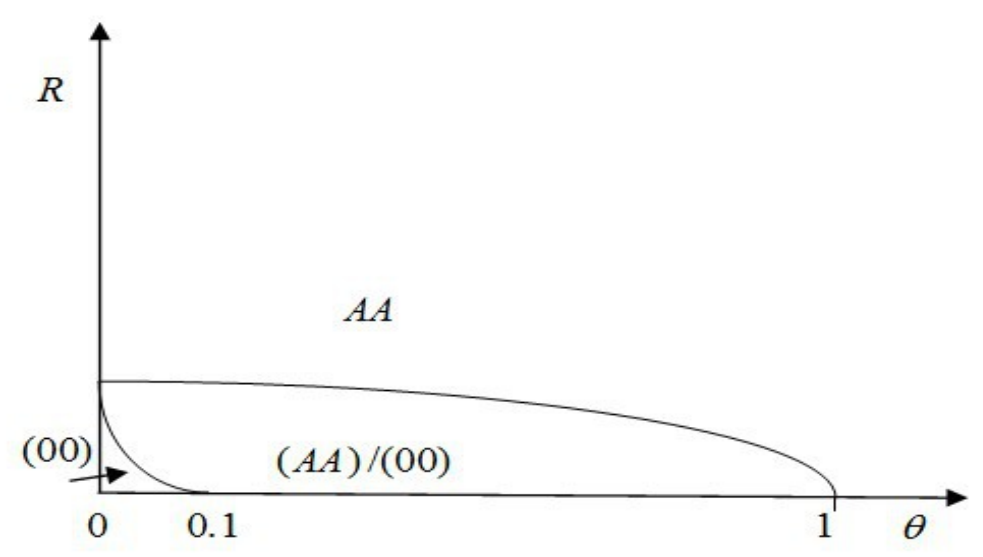

Figure 3. Optimal strategy under not full-covered market

As can be seen from the figure, when the reservation price $R$ and advertising influence parameter $\theta$ are small, two firms doing no action simultaneously is the only Nash equilibrium solution. Because when the two parameters are small, the profits of two firms change small. The little change will not affect the firms' choice. When the reservation price $R$ is larger enough, two firms both take the advertisement that is the Nash equilibrium solution. Through the above analysis, we can get proposition 3 as follows: 
Proposition 3. In the not full-covered market, if the reservation price $R$ is high enough, two firms will choose advertising simultaneously whatever the value of $\theta$ is.

The above analysis shows that when the two firms take advertising, due to the full-covered market and the intense competition, the firms must reduce the price with the demand no change. So the profits for two firms will decrease. Next we consider the case that under the not full-covered market, the two firms both choose the advertisement. We find $\frac{\partial p_{i}}{R}>0, \frac{\partial p_{i}}{\theta}<0$, $\frac{\partial q_{i}}{R}>0$ and $\frac{\partial q_{i}}{\theta}>0$ (see Appendix 2b). From the above results we can see that with the increasing of parameter $R$ and $\theta$, the product demand will increase; and the price is increasing when the consumer's reservation price increases and decreasing when the advertising influence parameter increases. When the reservation price $R$ is large enough, no matter how value of $\theta$ between 0 and 1 , the influence of $\theta$ on price is far lower than that of $R$ on price, so the price will increase when $R$ is large enough. Therefore, when the consumer's reservation price $R$ is large enough, the two firms would choose advertising. With the increasing of the price and the demand, the profits of the two firms will increase eventually. Note that this case just occurs in the not full-covered market, because the increased demand by advertising comes from the external market outside the two firms, rather than through snatching rival's market share to achieve.

\subsection{In two kinds of market, the firm must choose one action to improve the competitive power-R\&D or advertising.}

When the firms must increase the consumer's utility by choosing R\&D or advertising, the profits for the firms are listed in the Table 3:

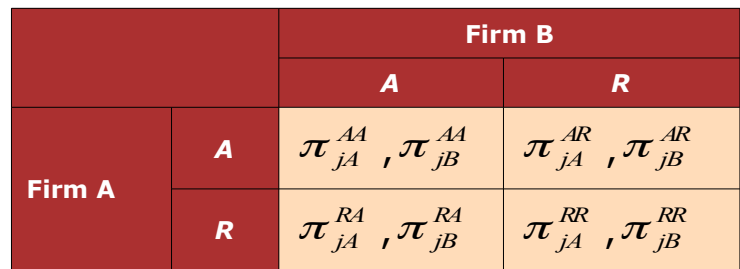

Table 3. The profits with R\&D or advertising

Where $\pi_{j i}^{K}$ is the profit for firm $i$ in market $j$ choosing strategy $K, i \in(A, B), j \in(F, D)$ and $K \in\{(A, A),(A, R),(R, A),(R, R)\} . A$ is denoted that the firm chooses advertising and $R$ is denoted that the firm chooses R\&D. Further, we use the abbreviations $A A$ to denote the strategy for two firms, and the first (second) letter to denote the action for firm $A$ (firm $B$ ). 
Because we have given the related profits when two firms choose pure strategies $A A$ and $R R$. The following we will list the profits of one firm taking R\&D and another taking advertising. Demand function about the two cases is in Appendix 1e and $1 \mathrm{f}$.

When the market is full-covered,

$$
\begin{gathered}
\pi_{F A}^{A R}=-\frac{M^{2}(-2+\theta)(-7+3 \theta)^{2}}{(-16+9 \theta)^{2}}=\pi_{F B}^{R A} \\
\pi_{F A}^{R A}=-\frac{M^{2}(-3+2 \theta)^{2}}{-16+9 \theta}=\pi_{F B}^{A R}
\end{gathered}
$$

When the market is not full-covered,

$$
\begin{gathered}
\pi_{D A}^{A R}=-\frac{(-2+\theta)(-3+2 \theta)(-M-2 R+M \theta+R \theta)^{2}(41-37 \theta+8 \theta)^{2}}{(-1+\theta)\left(716-1363 \theta+951 \theta^{2}-288 \theta^{3}+32 \theta^{4}\right)^{2}}=\pi_{D B}^{R A} \\
\pi_{D A}^{R A}=\frac{(-3+\theta)(-7+4 \theta)^{2}(-M-2 R+M \theta+R \theta)^{2}}{(-1+\theta)\left(716-1363 \theta+951 \theta^{2}-288 \theta^{3}+32 \theta^{4}\right)}=\pi_{D B}^{A R}
\end{gathered}
$$

Analyze the above results, we will get proposition 4 as follows:

Proposition 4. When the firm must take action to improve the competitiveness, whatever in the full-covered market or not full-covered market, it would not happen that two firms both choose advertising.

In the full-covered market, we compare the profits in different strategies and get strategy $R R$ is unique Nash equilibrium solution. In the front, we have discussed strategy $R R$ and strategy $A A$, and know under the full-covered market, strategy $A A$ is not Nash equilibrium solution. By comparing strategy $R R$ and strategy $A A$, we know that in these strategies, each firm's market share has no change, but the price of the product in strategy $R R$ is larger than that in strategy $A A$. Next we will discuss the related profit of two firms in strategy $A A$, strategy $R A$ and strategy $A R$. Strategy $R A$ represents the symmetric case of strategy $A R$, and thus, without loss of generality, we omit the discussion of strategy $R A$ to avoid redundancy. In strategy $A R$, one firm takes advertisement and another takes R\&D which makes the value of products increase. Because one firm doesn't pay the extra cost for advertising, it would 
continue to strengthen the advertising to increase the value of products and grab more market share. The market is fully-covered, one firm only grabs the market share from another firm. In this situation the competing firm in order to keep its market shared, must pay more money on $R \& D$. The competition would become intense and the price of the product will decrease. But this competition is not intense infinitely because $R \& D$ has the cost. The firm taking R\&D will consider the profit and the cost at the same time. This reason weakens and restrains the competition in the market. So the profits of two firms in strategy $A R$ will be greater than that in strategy $A A$. Comparing strategy $A R$ and strategy $A A$, the former is better for firms. So in the full-covered market, the two firms will not choose the advertising simultaneously.

In the not full-covered market, we get the optimal strategy about parameter $R$ and $\theta$ in Figure 4 .

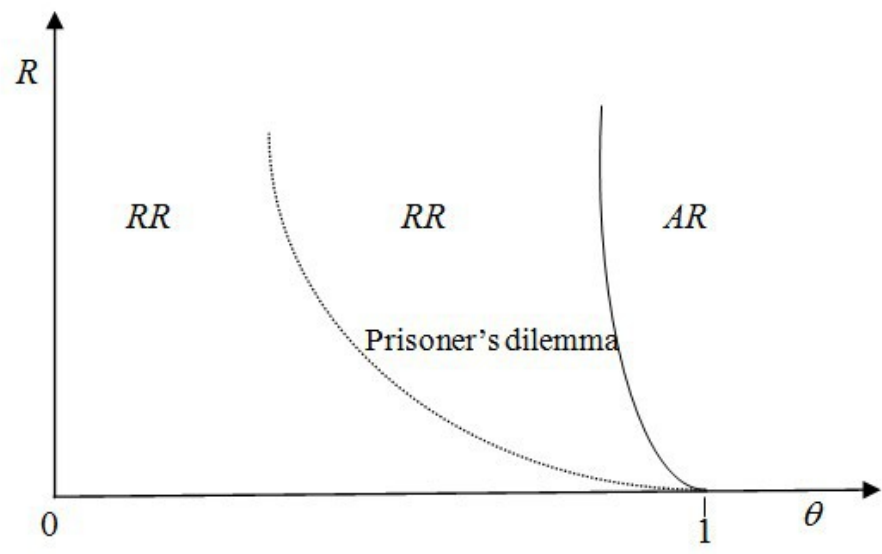

Figure 4. The optimal strategy in not full-covered market

It can be seen that when $\theta$ closes to 1 , strategy $A R$ (or strategy $R A$ ) is the Nash equilibrium solution for two firms. In the not full-covered market, when the firm takes the advertisement, the additional market demand would occupy from the market outside the two firms rather than at the expense of reducing price. The market demand and the price may increase at the same time which is related to $\theta$. From the figure we can see that no matter how the parameters $R$ and $\theta$ change, strategy $A A$ will not be the Nash equilibrium solution for two firms. Because when two firms take the advertisement simultaneously, the advertisement effect parameter $\theta$ is the same. In order to get more profit, they will reduce the price to get more market share which intensifies the competition in the market, so their profits will decrease. In strategy $R R$, the effect of R\&D is related to the cost of each firm's R\&D; and in strategy $A R, e_{i}$ and $\theta$ are different. So strategy $R R$ and strategy $A R$ would be the Nash equilibrium solution for two firms with the change of $R$ and $\theta$. Strategy $A A$ is never the Nash equilibrium solution under not full-covered market. 


\section{Conclusion}

In this paper we establish a model that the two competing firms choose the different measures to increase their competitiveness, where the different choice will have affect on the price. We analyze two cases of market-full-covered market and not full-covered market. From the research we find that two competing firms often take the same action such as take no action simultaneously or take some investment to improve the utility of the consumers simultaneously. We find that whether in full-covered market or not full-covered market, it is not a Nash equilibrium solution that a firm takes the action to improve the product value, another takes no action. To calculate simply we think advertisement insertion has no extra cost for the network externality propaganda. People would think since advertising can increase the utility of the consumer, it is better to take more advertisement. But the study finds that in the full-covered market when firms just can choose advertisement or no action, the two firms don't choose advertising simultaneously. Because advertising will increase the competition in the market, with the intense competition the two firms' profits will decrease. Since the development of the economy and technology, two firms must take some investment to improve the competitiveness. We find that under this situation two firms both advertising is not the Nash equilibrium still regardless of full-covered market or not full-covered market.

In this paper we assume using the advertisement to public the net work externality propaganda with no extract cost; competing firms just facing two choices; and the competing firms without cooperation. In future research, we will further study more conditions which are not involved in this paper, such as the two competing firms join an alliance to make R\&D or advertising. Hope that these researches could help on researching the competing firms in the market.

\section{References}

Anderson, E.T., \& Simester, D. (2013). Advertising in a Competitive Market: The Role of Product Standards, Customer Learning, and Switching Costs. Journal of Marketing Research, 50(4), 489-504. http://dx.doi.org/10.1509/jmr.11.0538

Baye, M.R., \& Morgan, J. (2009). Brand and price advertising in online markets. Management Science, 55(7), 1139-1151.

Dutta, S., Narasimhan, O., \& Rajiv, S. (1999). Success in high-technology markets: Is marketing capability critical? Marketing Science, 18(4), 547-568.

http://dx.doi.org/10.1287/mksc.18.4.547

Fosfuri, A., \& Giarratana, M.S. (2009). Masters of War: Rivals' Product Innovation and New Advertising in Mature Product Markets. Management Science, 55(2), 181-191. http://dx.doi.org/10.1287/mnsc. 1080.0939 
Gardete, P.M. (2013). Cheap-Talk Advertising and Misrepresentation in Vertically Differentiated Markets. Marketing Science, 32(4), 609-621. http://dx.doi.org/10.1287/mksc.2013.0772

Grossmann, V. (2008). Advertising, in-house R\&D, and growth. Oxford Economic Papers-New Series.

Hotelling, H. (1929). Stability in Competition. The Economic Journal, 39(153), 41-57. http://dx.doi.org/10.2307/2224214

Mizik, N., \& Jacobson, R. (2003). Trading off between value creation and value appropriation: The financial implications of shifts in strategic emphasis. Journal of Marketing, 67(1), 63-76. http://dx.doi.org/10.1509/jmkg.67.1.63.18595

Ofek, E., \& Sarvary, M. (2003). R\&D, marketing, and the success of next-generation products. Marketing Science, 22(3), 355-370. http://dx.doi.org/10.1287/mksc.22.3.355.17742

Sosa, M.L. (2009). Application-Specific R\&D Capabilities and the Advantage of Incumbents: Evidence from the Anticancer Drug Market. Management Science, 55(8), 1409-1422. http://dx.doi.org/10.1287/mnsc.1090.1027

Steenkamp, J., \& Fang, E. (2011). The Impact of Economic Contractions on the Effectiveness of R\&D and Advertising: Evidence from US Companies Spanning Three Decades. Marketing Science, 30(4), 628-645. http://dx.doi.org/10.1287/mksc.1110.0641

Xu, Y., Gurnani, H., \& Desiraju, R. (2010) Strategic supply chain structure design for a proprietary component manufacturer. Production and Operations Management, 19(4), 371-389. http://dx.doi.org/10.1111/j.1937-5956.2009.01116.x

\section{Appendix 1}

a. The demand functions in the full-covered market just R\&D:

$$
\begin{aligned}
& q_{F A}^{00}=\frac{M+p_{B}-p_{A}}{2}, q_{F B}^{00}=\frac{M+p_{A}-p_{B}}{2}, q_{F A}^{R 0}=\frac{M+p_{B}-p_{A}+e_{A}}{2} \\
& q_{F B}^{R 0}=\frac{M+p_{A}-p_{B}-e_{A}}{2}, q_{F A}^{R R}=\frac{M+p_{B}-p_{A}+e_{A}-e_{B}}{2}, q_{F B}^{R R}=\frac{M+p_{A}-p_{B}+e_{B}-e_{A}}{2}
\end{aligned}
$$

b. The demand functions in the not full-covered market just R\&D:

$$
q_{D A}^{00}=\frac{M+2 R+p_{B}-3 p_{A}}{2}, q_{D B}^{00}=\frac{M+2 R+p_{A}-3 p_{B}}{2}, q_{D A}^{R 0}=\frac{M+2 R+p_{B}-3 p_{A}+3 e_{A}}{2},
$$


$q_{D B}^{R 0}=\frac{M+2 R+p_{A}-3 p_{B}-e_{A}}{2}, q_{D A}^{R R}=\frac{M+2 R+p_{B}-3 p_{A}+3 e_{A}-e_{B}}{2}$,

$q_{D B}^{R R}=\frac{M+2 R+p_{A}-3 p_{B}+3 e_{B}-e_{A}}{2}$

c. The demand functions in the full-covered market just advertisement:

$$
\begin{aligned}
& q_{F A}^{00}=\frac{M+p_{B}-p_{A}}{2}, q_{F B}^{00}=\frac{M+p_{A}-p_{B}}{2}, q_{F A}^{A 0}=\frac{M+p_{B}-p_{A}}{2-\theta}, q_{F B}^{A 0}=\frac{(1-\theta) M+p_{A}-p_{B}}{2-\theta}, \\
& q_{F A}^{A A}=\frac{(1-\theta) M+p_{B}-p_{A}}{2(1-\theta)}, q_{F B}^{A A}=\frac{(1-\theta) M+p_{A}-p_{B}}{2(1-\theta)}
\end{aligned}
$$

d. The demand functions in the not full-covered market just advertisement:

$$
\begin{aligned}
& q_{D A}^{00}=\frac{M+2 R+p_{B}-p_{A}}{2}, q_{D B}^{00}=\frac{M++2 R+p_{A}-p_{B}}{2}, \\
& q_{D A}^{A 0}=\frac{(1-\theta) M+(2-\theta) R+(1-\theta) p_{B}-(3-2 \theta) p_{A}}{(2-\theta)(1-\theta)}, q_{D B}^{A 0}=\frac{(1-\theta) M+(2-\theta) R+p_{A}-(3-\theta) p_{B}}{2-\theta}, \\
& q_{D A}^{A A}=\frac{(1-\theta) M+2 R+p_{B}-3 p_{A}}{2(1-\theta)}, q_{D B}^{A A}=\frac{(1-\theta) M+2 R+p_{A}-3 p_{B}}{2(1-\theta)}
\end{aligned}
$$

e. The demand functions in the full-covered market with R\&D or advertisement:

$$
q_{F A}^{A R}=\frac{M-e_{B}+p_{B}-p_{A}}{2-\theta}, q_{F B}^{A R}=\frac{(1-\theta) M+e_{B}+p_{A}-p_{B}}{2-\theta}
$$

f. The demand functions in the not full-covered market with R\&D or advertisement:

$$
\begin{aligned}
& q_{D A}^{A R}=\frac{\left(M-e_{B}+p_{B}-p_{A}\right)(1-\theta)+\left(R-p_{A}\right)(2-\theta)}{(2-\theta)(1-\theta)} \\
& q_{D B}^{A R}=\frac{\left((1-\theta) M+e_{B}+p_{A}-p_{B}\right)+(2-\theta)\left(R+e-p_{B}\right)}{2-\theta}
\end{aligned}
$$




\section{Appendix 2}

a. In full-covered market, the price and the demand in Strategy 00 and Strategy $A A$

$p_{F i}^{00}=M, p_{F i}^{R R}=M, q_{F i}^{00}=M / 2, q_{F i}^{R R}=M / 2$

b. Sensitivity analysis for price and demand

$\frac{\partial p_{i}}{R}=\frac{2}{5}>0, \frac{\partial p_{i}}{\theta}=-\frac{M}{5}<0, \frac{\partial q_{i}}{R}=-\frac{3}{5(-1+\theta)}>0, \frac{\partial q_{i}}{\theta}=-\frac{6 R}{10(-1+\theta)^{2}}>0$

Journal of Industrial Engineering and Management, 2014 (www.jiem.org)

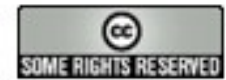

Article's contents are provided on a Attribution-Non Commercial 3.0 Creative commons license. Readers are allowed to copy, distribute and communicate article's contents, provided the author's and Journal of Industrial Engineering and Management's names are included. It must not be used for commercial purposes. To see the complete license contents, please visit http://creativecommons.org/licenses/by-nc/3.0/. 